Еркелдесова Гульзада, докторант $\mathrm{PhD}$ Казахский университет путей сообщения, г. Алматы, Республика Казахстан E-mail: gulzada888@mail.ru ORCID ID: 0000-0001-6527-7180

\title{
ДИСПЕТЧЕРИЗАЦИЯ ДВИЖЕНИЯ ВЫСОКОСКОРОСТНОГО ТРАНСПОРТА В УСЛОВИЯХ ВРЕМЕННЫХ ОГРАНИЧЕНИЙ
}

\author{
Gulzada Yerkeldessova, Doctoral student $\mathrm{PhD}$ \\ Kazakh university ways of communications \\ Almaty, the Republic of Kazakhstan \\ E-mail: gulzada888@mail.ru \\ ORCID ID: 0000-0001-6527-7180
}

\section{DISPATCHING MOTION HIGH SPEED TRANSPORT IN THE CONDITIONS OF TEMPORARY LIMITATIONS}

\begin{abstract}
Annotation: The introduction of high-speed rail transport imposes new requirements for safety and traffic control. The integration of modern satellite technologies, digital communication systems and data transmission, ensured the highest level of high-speed rail transport quality. As many researchers note, it is important not only to equip rolling stock with satellite communications, but also to ensure effective processing of their motion parameters based on automated information processing and decisionmaking technologies.
\end{abstract}

Keywords: high-speed railway transport, automated dispatch control system, mobile connection.

Аннотация: Внедрение высокоскоростного железнодорожного транспорта предьявляют новые требования к безопасности и управлению движения. Интеграция современных спутниковых технологий, иифровых систем связи и передачи данных, обеспечили высочайший уровень качества высокоскоростного железнодорожного транспорта. Как отмечают многие исследователи, важно не только оснастить подвижные составы средствами спутниковой связи, но также обеспечить эффективную обработку параметров их движения на основе автоматизированных информационных технологий обработки данных и принятия решений.

Ключевые слова: высокоскоростной железнодорожный транспорт, автоматизированная система диспетчерского управления, мобильная связь.

Транспортная система Республики Казахстан, в том числе железнодорожный (ж.д.) транспорт, является важным звеном экономики. При этом в последние годы, следуя мировым трендам развития техники и технологий, на ж.-д. транспорте в Казахстане активно стали развивать направление по внедрению высокоскоростного подвижного состава. Современные высокоскоростные железнодорожные транспортные системы, представляет сложную иерархическую систему. Интеграция современных спутниковых технологий, цифровых систем связи и передачи данных, обеспечили высочайший уровень качества высокоскоростного железнодорожного транспорта (далее - ВСЖТ). Как отмечают многие исследователи [1-3], важно не только оснастить подвижные ВСЖТ средствами спутниковой связи, но также обеспечить эффективную обработку параметров движения ВСЖТ на основе автоматизированных информационных технологий обработки данных и принятия решений.

Технические науки транспортная система
Материалы Международной практической интернет-конференции «Актуальные Проблемы Науки» 
Поэтому обеспечение безопасности движения, своевременности выполнения перевозок достаточно актуальной задачей управления и целью наших исследований является разработка подсистемы связи и передачи данных в системе диспетчерского управления ВСЖТ.

Основой разрабатываемой системы послужит стандарт связи, удовлетворяющий необходимым требованиям для функционирования системы в целом. Например, в качестве стандарта мобильной связи можно использовать стандарт GSM, см. рисунок.

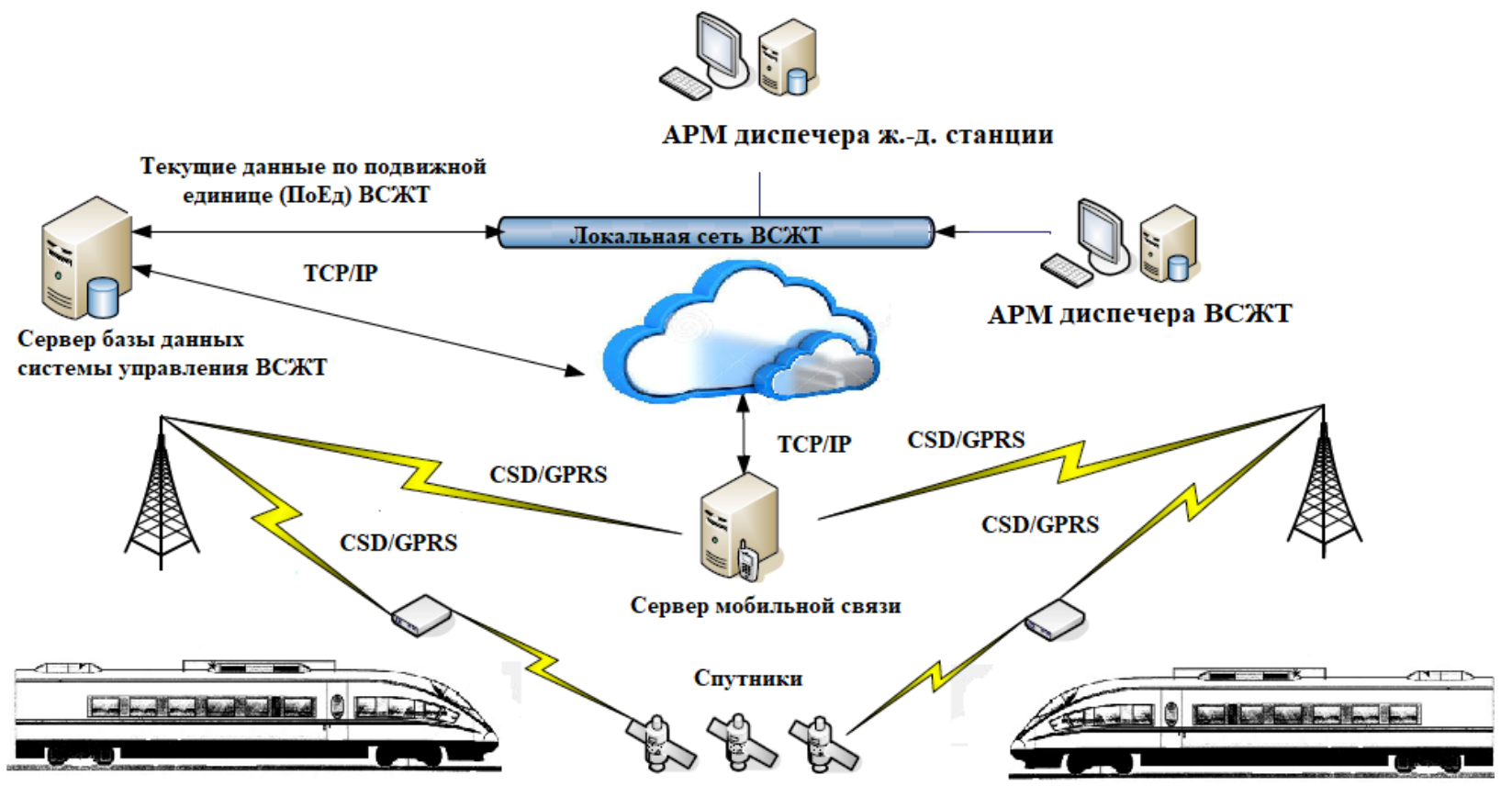

Рисунок. Схема информаџионного обмена системь координаџии и диспетчеризации движения ВСЖТ

Для полноценного функционирования автоматизированной системы диспетчерского управления (АСДУ) необходимо использование навигационного оборудования и бортовых интеллектуальных комплексов [1], которые установлены на подвижных средствах ВСЖТ. Они обеспечивают передачу информации о местонахождении ВСЖТ, а также принятие управленческих решений. При этом возникает следующая дилемма - увеличение количества ВСЖТ увеличит сетевую нагрузку в каналах связи. Это, в свою очередь, потребует применять частоты в большем диапазоне в сравнении с обычными для мобильных систем связи. По мере развития ВСЖТ в Республике Казахстан возникнет необходимость в разработке методов и моделей, направленных на повышение эффективности управления ресурсами в технологических процессах автоматизации системы координации и диспетчеризации движения ВСЖТ. Тогда необходимо будет решать задачи по оцениванию существующих систем GPRS, обеспечивающих связь и передачу данных ВСЖТ.

Отметим, что в разрабатываемой системе необходимо предусмотреть режимы равнодоступности подвижных средств ВСЖТ к предоставленным каналам связи. Абоненты должны иметь технологически равные возможности передавать пакеты данных, касающиеся состояния ВСЖТ или голосовые вызовы. Концептуально полагаем, что обслуживать голосовой трафик необходимо предварительно прервав сервис по пакетам GPRS. Это можно регулировать приоритетностью вызова или передачи данных. В системе

Технические науки транспортная система
Материалы Международной практической интернет-конференции «Актуальные Проблемы Науки» 
также необходимо предусмотреть буфер (накопитель) по обслуживанию лишь GPRS пакетов.

Таким образом, ближайшие цели исследований могут быть сформулированы так: 1) формализовать задачи передачи навигационных данных для системы координации движения ВСЖТ с учетом оптимизации использования ресурсов сети GPRS; 2) выполнить оценку емкости и возможностей имеющейся сети GPRS на ВСЖТ для обеспечения необходимого качества услуг и скорости передачи данных.

В настоящее время сформированы цели исследований и план работ по их реализации. В последующих работах предполагается освещение концептуальных моделей информационного обмена и автоматизированной диспетчеризации движения ВСЖТ, а также модели на основе агентно-ориентированной парадигмы.

\section{ЛИТЕРАТУРА}

1. Скалозуб, В. В., Соловьев, В. П., Жуковицкий, И. В., \& Гончаров, К. В. (2013). Интеллектуальные транспортные системы железнодорожного транспорта (основы инновационных технологий): пособие.

2. Гапанович В. А., Розенберг И. Н. Основные направления развития интеллектуального железнодорожного транспорта //Железнодорожный транспорт. - 2011. - №. 4. - C.5-11.

3. Агафонов, Д. В. (2018). Анализ целесообразности отделения железнодорожной инфраструктуры высокоскоростных магистралей в Российской Федерации. Интернетжурнал: Науковедение, 9(1 (38)). 